\title{
JOURNAL.RU
}

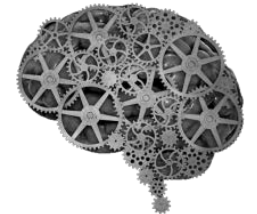

COMPANY GROUP

"INTELLEKT"

Мокина М. И.

ФГОБУ ВПО Финансовый университет при Правительстве РФ

Москва, Россия

Научный руководитель: Савина Е.О.

doi: 10.18411/lj2016-7-2-11

idsp 000001: lj2016-16-2-11

\section{Анализ налоговых поступлений в бюджеты разных уровней на примере Ярославской области}

Недостаточная разработанность теоретического обоснования направлений развития налогово-бюджетной системы приводит к недостаточному обеспечению бюджетов соответствующими доходами и неопределенности в методах разграничения обязательных платежей между бюджетами всех уровней бюджетной системы.

Цель работы - анализ поступлений налогов и сборов в бюджеты разных уровней за 2006-2012 гг. в Ярославской области. В данной таблице представлена структура поступлений основных администрируемых доходов Ярославской области по уровням бюджета РФ в январе-феврале 2016 года.

Таблица 1

Структура поступлений основных администрируемых доходов от Ярославской области по уровням бюджета РФ за январь-февраль 2016 года[2]

\begin{tabular}{|c|c|c|c|c|c|c|}
\hline \multirow{3}{*}{$\begin{array}{c}\text { Администрируемые } \\
\text { доходы }\end{array}$} & \multirow{2}{*}{\multicolumn{2}{|c|}{$\begin{array}{c}\text { Поступило в } \\
\text { консолидированный } \\
\text { бюджет РФ }\end{array}$}} & \multicolumn{4}{|c|}{ в том числе : } \\
\hline & & & \multicolumn{2}{|c|}{$\begin{array}{c}\text { в федеральный } \\
\text { бюджет }\end{array}$} & \multicolumn{2}{|c|}{$\begin{array}{r}\text { в консолидирован. } \\
\text { бюджет субъекта РФ }\end{array}$} \\
\hline & млн. руб. & прирост \% & млн. руб. & $\begin{array}{c}\text { прирост } \\
\%\end{array}$ & млн. руб. & прирост \% \\
\hline $\begin{array}{c}\text { Всего поступило } \\
\text { доходов }\end{array}$ & 21535 & 5,68 & 11831,3 & 15,96 & 9703,7 & $-4,63$ \\
\hline Налоговые доходы & 21520,6 & 5,68 & 11818,3 & 15,97 & 9702,3 & $-4,64$ \\
\hline Налог на прибыль & 3596,4 & 15,84 & 69,6 & 38,2 & 3526,9 & 15,47 \\
\hline НДФЛ & 2657,4 & 9,34 & $\mathrm{X}$ & $\mathrm{X}$ & 794 & 9 \\
\hline НДС & 4102 & 18,85 & 4102 & 18,85 & $\mathrm{X}$ & $\mathrm{X}$ \\
\hline Акцизы & 12771,4 & 0,47 & 7562,1 & 14,27 & 5209,7 & $-14,5$ \\
\hline
\end{tabular}




\begin{tabular}{|c|c|c|c|c|c|c|}
\hline Торговый сбор & 0 & 0 & $\mathrm{X}$ & $\mathrm{X}$ & 0 & 0 \\
\hline $\begin{array}{c}\text { Налог на имущество } \\
\text { физическх лиц }\end{array}$ & 14,2 & $-39,75$ & $\mathrm{X}$ & $\mathrm{X}$ & 14,2 & $-39,75$ \\
\hline $\begin{array}{c}\text { Налог на имущество } \\
\text { организаций }\end{array}$ & 153,5 & 22,95 & $\mathrm{X}$ & $\mathrm{X}$ & 153,5 & 22,95 \\
\hline Транспортный налог & 98,3 & $-13,74$ & $\mathrm{X}$ & $\mathrm{X}$ & 98,3 & $-13,74$ \\
\hline $\begin{array}{c}\text { Налог на игорный } \\
\text { бизнес }\end{array}$ & 0,5 & 58,05 & $\mathrm{X}$ & $\mathrm{X}$ & 0,5 & 58,05 \\
\hline Земельный налог & 394,8 & 13,45 & $\mathrm{X}$ & $\mathrm{X}$ & 394,8 & 13,45 \\
\hline НдПИ & 1,1 & $-28,57$ & 0,1 & 0 & 1 & $-30,31$ \\
\hline $\begin{array}{c}\text { Водный налог } \\
\text { объектами животного } \\
\text { мира и водных биоло- } \\
\text { гических ресурсов }\end{array}$ & 1,7 & 49,38 & 1,7 & 49,38 & $\mathrm{X}$ & $\mathrm{X}$ \\
\hline $\begin{array}{c}\text { Государственная } \\
\text { пошлина }\end{array}$ & 4,024 & $-22,58$ & 0,002 & -50 & 0,022 & $-8,52$ \\
\hline
\end{tabular}

Можно отметить, что основная часть поступлений увеличилась.

Наибольший относительный рост наблюдается по налогу на игорный бизнес $(58,08 \%)$, водному налогу $(49,38 \%)$, НДС $(18,85 \%)$, налогу на имущество организаций $(22,95 \%)$. Стоит отметить, что снизились поступления налоговых доходов в консолидированный бюджет области. Также снизилось поступление акцизов, налога на имущество физических лиц, транспортного налога, НДПИ и сборов за пользование объектами животного мира и за пользование объектами водных биологических ресурсов.

В таблице 2 представлена доля налоговых поступлений во всех доходах Ярославской области в 2006 - 2012 годах.

Таблииа 2 Доля налогов, сборов и иных обязательных платежей во всех доходах Ярославской области в 2006 - 2012

\begin{tabular}{|c|c|c|c|c|c|c|c|}
\hline & 2006 & 2007 & 2008 & 2009 & 2010 & 2011 & 2012 \\
\hline $\begin{array}{c}\text { Всего поступило } \\
\text { налоговых и других } \\
\text { доходов }\end{array}$ & 31501,63 & 44918,13 & 50057,80 & 46635,25 & 57756,69 & 70747,23 & 87912,47 \\
\hline Налоговые доходы & 31475,52 & 44891,17 & 50036,10 & 46613,03 & 57737,35 & 70722,30 & 87894,18 \\
\hline $\begin{array}{c}\text { Доля налоговых } \\
\text { поступлений }\end{array}$ & 99,92 & 99,94 & 99,96 & 99,95 & 99,97 & 99,96 & 99,98 \\
\hline
\end{tabular}

Доля налогов, сборов и иных обязательных платежей в налоговых и других доходах Ярославской области с каждым годом увеличивается.

В таблице 3 представлены поступления налогов, сборов и иных обязательных платежей в бюджетную систему РФ в Ярославской области в 2006 - 2012 гг. по различным налогам и сборам. Таблица составлена автором на основе сведений, представленных на сайте ФНС. 
Таблийа 3

Поступление налогов, сборов и иных обязательных платежей в бюджетную систему РФ в Ярославской области в 2006 - 2012 гг., млн. руб.

\begin{tabular}{|c|c|c|c|c|c|c|c|}
\hline & 2006 & 2007 & 2008 & 2009 & 2010 & 2011 & 2012 \\
\hline $\begin{array}{c}\text { Всего поступило } \\
\text { налоговых и других } \\
\text { доходов }\end{array}$ & 31501,63 & 44918,13 & 50057,80 & 46635,25 & 57756,69 & 70747,23 & 87912,47 \\
\hline Налоговые доходы & 31475,52 & 44891,17 & 50036,10 & 46613,03 & 57737,35 & 70722,30 & 87894,18 \\
\hline $\begin{array}{c}\text { Налог на прибыль } \\
\text { организаций }\end{array}$ & 8917,05 & 9201,88 & 8589,86 & 6860,01 & 8328,71 & 9466,31 & 12170,68 \\
\hline НДФЛ & 7648,79 & 9830,87 & 12864,30 & 11382,86 & 12354,71 & 14001,27 & 15387,36 \\
\hline НДС & 5607,16 & 9378,61 & 8750,58 & 7390,28 & 9886,14 & 11019,60 & 13764,61 \\
\hline Акцизы & 4570,21 & 11116,36 & 13533,62 & 14051,66 & 19392,81 & 27734,39 & 36104,60 \\
\hline $\begin{array}{c}\text { Налог на } \\
\text { имущество } \\
\text { физических лиц } \\
\end{array}$ & 80,94 & 137,61 & 179,26 & 281,18 & 192,85 & 58,24 & 264,44 \\
\hline $\begin{array}{c}\text { Налог на } \\
\text { имущество } \\
\text { организаций } \\
\end{array}$ & 1969,25 & 2362,97 & 2672,15 & 3299,88 & 3782,44 & 3934,46 & 4702,04 \\
\hline $\begin{array}{c}\text { Транспортный } \\
\text { налог } \\
\end{array}$ & 242,54 & 182,84 & 391,21 & 507,45 & 613,11 & 702,01 & 786,44 \\
\hline $\begin{array}{c}\text { Налог на игорный } \\
\text { бизнес }\end{array}$ & 244,39 & 306,31 & 292,67 & 115,29 & -205 & 2,10 & 1,55 \\
\hline Земельный налог & 534,26 & 739,53 & 885,99 & 1407,28 & 1394,55 & 1622,18 & 2049,01 \\
\hline НДПИ & 12,32 & 17,26 & 21,89 & 16,13 & 18,68 & 18,33 & 26,88 \\
\hline Водный налог & 89,52 & 94,82 & 85,65 & 33,80 & 10,15 & 5,77 & 11,01 \\
\hline $\begin{array}{c}\text { Сборы за } \\
\text { пользование } \\
\text { объектами } \\
\text { животного мира } \\
\text { и водных } \\
\text { биологических } \\
\text { ресурсов }\end{array}$ & 2,71 & 3,43 & 3,71 & 3,96 & 4,08 & 4,37 & 4,29 \\
\hline $\begin{array}{c}\text { Государственная } \\
\text { пошлина, сборы }\end{array}$ & 65,16 & 80,91 & 98,01 & 135,39 & 187,17 & 183,90 & 203,16 \\
\hline $\begin{array}{c}\text { Остальные налоги и } \\
\text { сборы }\end{array}$ & 1491,22 & 1437,77 & 1667,2 & 1127,86 & 1776,95 & 1969,37 & 2418,11 \\
\hline
\end{tabular}

В ходе работы была рассчитана доля отдельных налогов в поступлениях

налогов, сборов и иных обязательных платежей в бюджетную систему РФ в

Ярославской обл. в 2006-2012 гг. на основе сведений, представленных ФНС.

Таблицча 4

Доля отдельных налогов в поступлениях налогов, сборов и иных обязательных платежей в бюджетную систему РФ в Ярославской области в 2006 - 2012 2, \%.

\begin{tabular}{|c|c|c|c|c|c|c|c|}
\hline $\begin{array}{c}\text { Налоговые доходы, } \\
\text { млн.руб }\end{array}$ & 2006 & 2007 & 2008 & 2009 & 2010 & 2011 & 2012 \\
\hline $\begin{array}{c}\text { Налог на прибыль } \\
\text { организаций }\end{array}$ & 28,33 & 20,50 & 17,17 & 14,72 & 14,43 & 13,39 & 13,85 \\
\hline НДФЛ & 24,30 & 21,90 & 25,71 & 24,42 & 21,40 & 19,80 & 17,51 \\
\hline НДС & 17,81 & 20,89 & 17,49 & 15,85 & 17,12 & 15,58 & 15,66 \\
\hline Акцизы & 14,52 & 24,76 & 27,05 & 30,15 & 33,59 & 39,22 & 41,08 \\
\hline $\begin{array}{c}\text { Налог на } \\
\text { имущесто } \\
\text { физическх лиц }\end{array}$ & 0,26 & 0,31 & 0,36 & 0,60 & 0,33 & 0,08 & 0,30 \\
\hline Налог на & 6,26 & 5,26 & 5,34 & 7,08 & 6,55 & 5,56 & 5,35 \\
\hline
\end{tabular}




\begin{tabular}{|c|c|c|c|c|c|c|c|}
\hline $\begin{array}{c}\text { имущество } \\
\text { организаций }\end{array}$ & 0,77 & 0,41 & 0,78 & 1,09 & 1,06 & 0,99 & 0,89 \\
\hline $\begin{array}{c}\text { Транспортный } \\
\text { налог }\end{array}$ & 0,78 & 0,68 & 0,58 & 0,25 & $-0,36$ & 0,00 & 0,00 \\
\hline $\begin{array}{c}\text { Налог на игорный } \\
\text { бизнес }\end{array}$ & 1,70 & 1,65 & 1,77 & 3,02 & 2,42 & 2,29 & 2,33 \\
\hline Земельный налог & 0,04 & 0,04 & 0,04 & 0,03 & 0,03 & 0,03 & 0,03 \\
\hline НдПИ & 0,28 & 0,21 & 0,17 & 0,07 & 0,02 & 0,01 & 0,01 \\
\hline Водный налог & 0,01 & 0,01 & 0,01 & 0,01 & 0,01 & 0,00 \\
\hline $\begin{array}{c}\text { Сборы за } \\
\text { пользование } \\
\text { объектами } \\
\text { животного мира } \\
\begin{array}{c}\text { и водных } \\
\text { биологических } \\
\text { ресурсов }\end{array}\end{array}$ & 0,21 & 0,18 & 0,20 & 0,29 & 0,32 & 0,26 & 0,23 \\
\hline $\begin{array}{c}\text { Государственная } \\
\text { пошлина, сборы }\end{array}$ & 4,74 & 3,20 & 3,33 & 2,42 & 3,08 & 2,78 & 2,75 \\
\hline $\begin{array}{c}\text { Остальные налоги и } \\
\text { сборы }\end{array}$ & & & & & & \\
\hline
\end{tabular}

Можно сделать вывод о том, что налоги на прибыль организаций, НДС, НДФЛ, акцизы являются бюджетообразующими. В 2006 г. доля налога на прибыль составила 28,33\%. Доля НДФЛ в 2008 году составила 25,4\%

Рассмотрим цепные темпы роста поступлений налогов, сборов и иных обязательных платежей в бюджетную систему РФ в Ярославской области.

Таблийа 5 Динамика поступлений налогов, сборов и иных обязательных платежей в бюджетную систему РФ в Ярославской области к предыдущему году в 2007 - 2012 г2.

\begin{tabular}{|c|c|c|c|c|c|c|}
\hline$\%$ & 2007 & 2008 & 2009 & 2010 & 2011 & 2012 \\
\hline $\begin{array}{c}\text { Всего поступило } \\
\text { налоговых и других } \\
\text { доходов } \\
\end{array}$ & 42,59 & 11,44 & $-6,84$ & 23,85 & 22,49 & 24,26 \\
\hline Налоговые доходы & 42,62 & 11,46 & $-6,84$ & 23,87 & 22,49 & 24,28 \\
\hline $\begin{array}{c}\text { Налог на прибыль } \\
\text { организаций }\end{array}$ & 3,19 & $-6,65$ & $-20,14$ & 21,41 & 13,66 & 28,57 \\
\hline НДФЛ & 28,53 & 30,86 & $-11,52$ & 8,54 & 13,33 & 9,90 \\
\hline НДС & 67,26 & $-6,70$ & $-15,55$ & 33,77 & 11,47 & 24,91 \\
\hline Акцизы & 143,24 & 21,75 & 3,83 & 38,01 & 43,01 & 30,18 \\
\hline $\begin{array}{c}\text { Налог на } \\
\text { имущество } \\
\text { физических лиц }\end{array}$ & 70,01 & 30,27 & 56,86 & $-31,41$ & $-69,80$ & 354,05 \\
\hline $\begin{array}{c}\text { Налог на } \\
\text { имущество } \\
\text { организаций } \\
\end{array}$ & 19,99 & 13,08 & 23,49 & 14,62 & 4,02 & 19,51 \\
\hline $\begin{array}{c}\text { Транспортный } \\
\text { налог }\end{array}$ & $-24,61$ & 113,96 & 29,71 & 20,82 & 14,50 & 12,03 \\
\hline $\begin{array}{c}\text { Налог на игорный } \\
\text { бизнес }\end{array}$ & 25,34 & $-4,45$ & $-60,61$ & $-277,81$ & $-101,02$ & $-26,19$ \\
\hline Земельный налог & 38,42 & 19,80 & 58,84 & $-0,90$ & 16,32 & 26,31 \\
\hline НДПИ & 40,10 & 26,83 & $-26,31$ & 15,81 & $-1,87$ & 46,64 \\
\hline Водный налог & 5,92 & $-9,67$ & $-60,54$ & $-69,97$ & $-43,15$ & 90,81 \\
\hline Сборы за & 26,57 & 8,16 & 6,74 & 3,03 & 7,11 & $-1,83$ \\
\hline
\end{tabular}




\begin{tabular}{|c|c|c|c|c|c|c|}
\hline $\begin{array}{c}\text { пользование } \\
\text { объектами } \\
\text { животного мира } \\
\text { и водных } \\
\text { биологических } \\
\text { ресурсов }\end{array}$ & & & & & & \\
\hline $\begin{array}{l}\text { Государственная } \\
\text { пошлина, сборы }\end{array}$ & 24,17 & 21,13 & 38,14 & 38,25 & $-1,75$ & 10,47 \\
\hline $\begin{array}{c}\text { Остальные налоги и } \\
\text { сборы }\end{array}$ & $-3,58$ & 15,96 & $-32,35$ & 57,55 & 10,83 & 22,79 \\
\hline
\end{tabular}

Отрицательное влияние на сокращение доходов консолидированного бюджета от налога на прибыль в 2008-2009 гг. оказали: снижение прибыли организаций на 31\%; прекращение действия законодательства региона по стимулированию экономического развития.

Рассмотрим распределение налогов в Ярославской области по бюджетам.

Распределение федеральных налогов Ярославской области по бюджетам в 2006 - 2012 г2.

\begin{tabular}{|c|c|c|c|c|}
\hline & \multicolumn{4}{|c|}{ Федеральные налоги и сборы, тыс.руб. } \\
\hline & Всего & $\begin{array}{c}\text { в федеральный } \\
\text { бюджет }\end{array}$ & $\begin{array}{c}\text { в консолидированный бюджет } \\
\text { субъекта РФ }\end{array}$ & $\begin{array}{c}\text { из него - в доходы } \\
\text { местн. бюджетов }\end{array}$ \\
\hline 2006 & 27401343 & 10342605 & 17058738 & 4879155 \\
\hline 2007 & 40209765 & 16391923 & 23817842 & 6529647 \\
\hline 2008 & 44261042 & 16822979 & 27438063 & 7883866 \\
\hline 2009 & 22357155 & 1690516 & 20666639 & 5404903 \\
\hline 2010 & 50360912 & 13717122 & 36643790 & 6274977 \\
\hline 2011 & 62722159 & 22036096 & 40686063 & 7089384 \\
\hline 2012 & 77945497 & 27809866 & 50135631 & 6260822 \\
\hline
\end{tabular}

Распределение региональных налогов Ярославской области по бюджетам в 2006 - 2012 22.

\begin{tabular}{|c|c|c|c|c|}
\hline & \multicolumn{4}{|c|}{ Региональные налоги и сборы, тыс.руб. } \\
\hline & Всего & $\begin{array}{c}\text { в федеральный } \\
\text { бюджет }\end{array}$ & $\begin{array}{c}\text { в консолидированный } \\
\text { бюджет субъекта РФ }\end{array}$ & $\begin{array}{c}\text { из него - в доходы } \\
\text { местных бюджетов }\end{array}$ \\
\hline 2006 & 2662927 & 0 & 2662927 & 103321 \\
\hline 2007 & 2701523 & 0 & 2701523 & -75249 \\
\hline 2008 & 3362762 & 0 & 3362762 & 3245 \\
\hline 2009 & 3037982 & 0 & 3037982 & 6712 \\
\hline 2010 & 4408620 & 0 & 4408620 & 812 \\
\hline 2011 & 4640090 & 0 & 4640090 & 1014 \\
\hline 2012 & 5491985 & 0 & 5491985 & 772 \\
\hline
\end{tabular}

Собственные доходы консолидированного бюджета Ярославской области в 2007 г. выросли на 26,5 \% и составили 30,2 млрд. руб. Поступление доходов в областной бюджет составило 17,7 млрд.руб. На 52\% увеличились поступления собственных доходов в местные бюджеты. 
Распределение местных налогов Ярославской области по бюджетам в 2006 - 2012 г2.

\begin{tabular}{|c|c|c|c|c|}
\hline & \multicolumn{4}{|c|}{ Местные налоги и сборы, тыс.руб. } \\
\hline 2006 & 654441 & $\begin{array}{c}\text { в федеральный } \\
\text { бюджет }\end{array}$ & $\begin{array}{c}\text { в консолидированный } \\
\text { бюджет субъекта РФ }\end{array}$ & $\begin{array}{c}\text { из него - в доходы } \\
\text { местных бюджетов }\end{array}$ \\
\hline 2007 & 940831 & 0 & 654441 & 654441 \\
\hline 2008 & 1098536 & 0 & 940831 & 940831 \\
\hline 2009 & 1622295 & 0 & 1098536 & 1698536 \\
\hline 2010 & 1609288 & 0 & 1622295 & 1609288 \\
\hline 2011 & 1683668 & 0 & 1609288 & 1683668 \\
\hline 2012 & 2315625 & 0 & 1683668 & 2315625 \\
\hline
\end{tabular}

В Ярославской области за местными бюджетами закреплены единые нормативы по НДФЛ (20\%), НДПИ, ЕСН (30\%). С 2007 года в Ярославской области применяется механизм передачи нормативов по отдельным видам налогов местным бюджетам взамен дотаций из областного фонда.

Распределение налогов, относящихся к специиальным налоговым режимам Ярославской области по бюджетам в 2006 - 2012 г2.

\begin{tabular}{|c|c|c|c|c|}
\hline & \multicolumn{4}{|c|}{ Налоги, относящиеся к специальным налоговым режимам } \\
\hline & Всего & $\begin{array}{c}\text { в федеральный } \\
\text { бюджет }\end{array}$ & $\begin{array}{c}\text { в консолидированный } \\
\text { бюджет субъекта РФ }\end{array}$ & $\begin{array}{c}\text { из него - в доходы } \\
\text { местных бюджетов }\end{array}$ \\
\hline 2006 & 756813 & -1 & 756814 & 344682 \\
\hline 2007 & 1039055 & 0 & 1039055 & 626797 \\
\hline 2008 & 1313761 & 0 & 1313761 & 464512 \\
\hline 2009 & 1199199 & 0 & 1199199 & 524390 \\
\hline 2010 & 1358525 & 0 & 1358525 & 619063 \\
\hline 2011 & 1676384 & 0 & 1676384 & 697877 \\
\hline 2012 & 2141072 & 0 & 2141072 & 462 \\
\hline
\end{tabular}

Большая доля федеральных налогов была зачислена в консолидированный

бюджет области. Региональные и местные налоги пополнили исключительно консолидированный бюджет субъекта, а местные налоги и сборы - доходы местных бюджетов.

На основании проведенного анализа можно сделать следующие выводы:

1. Лучшие позиции в 2008 году Ярославская область имела по акцизам на пиво, налогу на имущество организаций, НДФЛ.

2. Остаются слабыми позиции области по акцизам на нефтепродукты, налогу на игорный бизнес, земельному налогу.

3. Снизились показатели по налогу на прибыль.

4. Позиции Ярославской области по транспортному налогу, налогам на природные ресурсы, акцизам на алкогольную продукцию остаются низкими.

Региональная налоговая политика Ярославской области должна быть направлена на развитие внутреннего налогового потенциала, дальнейшее 
расширение налоговой базы за счет стимулирования экономической активности. Следует наладить эффективное взаимодействие с крупными налогоплательщиками, в т.ч. путем заключения среднесрочных взаимовыгодных соглашений о сотрудничестве. Может быть предусмотрено льготирование деятельности при наличии центра уплаты налога на прибыль на территории области. Следует оптимизировать состав налоговых льгот с учетом оценки их социальной и бюджетной эффективности.

Для поддержки промышленных организаций требуется принятие гибких условий для предоставления налоговых и государственных кредитов, субсидий, субвенций, льгот, а также освобождение от обязанности уплаты отдельных налогов на определенный период. Малому бизнесу может помочь целевая поддержка конкретных предприятий дифференцированным подходом к применению ряда федеральных законов и налоговыми льготами.

\section{Литература:}

1. "Налоговый кодекс РФ (часть I)" от 31.07.98 N146-Ф3 (ред. от 26.04.16) (с изм. и доп., вступ. в силу с 05.05.2016) [Электронный ресурс] // URL: http://base.consultant.ru/cons/cgi/online.cgi?req=doc;base=LAW;n=196452;fld $=134 ; \mathrm{dst}=61,0 ; \mathrm{rnd}=0.7490885777583891$ (дата обращения 02.05.16)

2. Федеральная налоговая служба // [Электронный ресурс] - Режим доступа. - URL: http://analytic.nalog.ru/ (дата обращения: 09.05.16) 